JPE (Jurnal Pendidikan Edutama) Vol. 5 No. 2 Juli 2018

P-ISSN : 2339-2258 (Print) E-ISSN: 2548-821X (Online)

http://ejurnal.ikippgribojonegoro.ac.id/index.php/JPE

\title{
EFEKTIVITAS MEDIA PEMBELAJARAN BERBASIS VISUAL OFFICE MIX PADA MAHASISWA PENDIDIKAN GURU SEKOLAH DASAR UNIVERSITAS PGRI MADIUN
}

\author{
Pinkan Amita Tri Prasasti \\ Fakultas Keguruan dan Ilmu Pendidikan, Universitas PGRI Madiun \\ Email: pinkan.amita@unipma.ac.id
}

\begin{abstract}
The purpose of this study is to determine the effectiveness of the use of visual media-based office mix media on science students in the third-semesterf PGSD study Program in Universitas PGRI Madiun in the academic year 2016/2017. This research was a quantitative research with experimental research method. The research design used in this research was Pre Experimental Design with Intact-Group Comparison. In this research, there were two groups selected, that were experimental group and control group. The research subjects were the third semester students consisting of 2 classes, consisting of 37 and 36 student. The data collection technique was done through test, observation and interview. The determination of control class and experiment class was done by simple random sampling technique. In analyzing the data, it was used tatistical methods with $t$-test ( $t$-test). From the hypothesis test analysis by using $t$-test with $5 \%$ significance level, it was obtained the value of $t$ obs $=19.18$ while $t$ table $=1.685$. BecauseTobs $>t$ table $\mathrm{Ha}$ is accepted. So it can be concluded that the use of visual-based media slide power point (office mix) is effective on learning Science.
\end{abstract}

Keywords: Learning Media Ofice Mix, PGSD, Universitas PGRI Madiun

\begin{abstract}
Abstrak Tujuan penelitian ini adalah untuk mengetahui efektivitas penggunaan media pembelajaran berbasis visual office mix pada pembelajaran sains mahasiswa semester 3 prodi PGSD Universitas PGRI Madiun Tahun Akademik 2016/2017. Penelitian ini merupakan jenis penelitian kuantitatif dengan metode penelitian eksperimen. Desain penelitian yang digunakan dalam penelitian ini adalah Pre experimental Design dan jenis penelitian yang digunakan Intact-Group Comparison. Dalam penelitian ini terdapat dua kelompok yang dipilih yaitu kelompok eksperimen dan kelompok kontrol. Subjek penelitiannya adalah mahasiswa semester 3 yang terdiri dari 2 kelas, yang berjumlah 37 dan 36. Teknik pemngumpulan data dilakukan melalui tes, observasi dan wawancara. Penentuan kelas kontrol dan kelas eksperimen dilakukan dengan teknik simple random sampling. Dalam menganalisis data, digunakan metode statistik dengan t-test (ujit). Dari analisis uji hipotesis soal tes menggunakan uji-t dengan taraf signifikansi $5 \%$, diperoleh nilai $t_{\text {hitung }}=19,18$ sedangkan $t_{\text {tabel }}=1,685$ Karena $t_{\text {hitung }}>$ $t_{\text {tabel }}$ maka $H_{a}$ diterima. Jadi dapat disimpulkan penggunaan media berbasis visual slide power point (office mix) efektif pada pembelajaran Sains mahasiswa PGSD Universitas PGRI Madiun Tahun Akademik pelajaran 2016/2017.
\end{abstract}

Kata Kunci: Media Pembelajaran Ofice Mix, PGSD, Universitas PGRI Madiun

\section{PENDAHULUAN}

Perkembangan teknologi dan informasi mempengaruhi pembaharuan yang pesat dalam pendidikan. Pemerintah dan masyarakat umum telah memberikan perhatian tentang kemajuan teknologi modern dalam memajukan dunia 
pendidikan, sehingga proses pembelajaran akan lebih menarik dan bermakna.

Berdasarkan hasil tes pendidikan yang dilakukan oleh Organisation for Economic Cooperative and Development (OECD) tahun 2015, dari 76 negara yang disurvei, Indonesia hanya mampu duduk di posisi 69. Data tersebut membuktikan bahwa peningkatan mutu pendidikan merupakan isu sentral di negara-negara maju maupun berkembang seperti Indonesia. Keberhasilan proses pembelajaran merupakan hal yang didambakan dalam pelaksanaan pendidikan disekolah. Maka proses pembelajaran diarahkan pada perluasan inovasi pembelajaran, karena itu perlu memberikan bekal penguasaan TIK (Teknologi Informasi dan Komunikasi) pada guru agar mereka mampu melaksanakan pembelajaran yang menggunakan multimedia secara baik, karena media pendidikan yang merupakan aspek nyata dari aplikasi teknologi pendidikan.

Criticos dalam Daryanto, 2010:14 enyatakan bahwa media adalah salah satu komponen komunikasi, yaitu sebagai pembawa pesan dari komunikator menuju komunikan. Namun dalam proses pembelajaran masih jarang guru memanfaatkan media. Berdasarkan hasil observasi proses kegiatan pembelajaran guru dalam menyampaikan materi masih belum mengoptimalkan inovasi pembelajaran dan menggunakan media yang belum menarik perhatian dan memasukkan konsep pembelajaran kepada peserta didik.. Guru jarang menggunakan media dalam mengajarkan pembelajaran IPA.

Ilmu pengetahuan alam (IPA) yaitu cara mencari tahu tentang alam secara sistematis untuk menguasai pengetahuan, fakta-fakta, konsep-konsep, prinsip-prinsip, proses penemuan, dan memiliki sikap ilmiah. Menurut kajian kurikulum 2013 di dalam pembelajaran IPA, peserta didik didorong untuk menemukan sendiri dan mentransformasi informasi kompleks. Peserta didik harus didorong untuk mengonstruksi pengetahuan didalam pikirannya, agar benar-benar memahami dan dapat menerapkan pengetahuan, peserta didik perlu didorong untuk bekerja memecahkan masalah, dan menemukan segala sesuatu untuk dirinya.

Berdasarkan hasil observasi yang dilakukan setelah melihat tenaga pendidik melaksanakan pembelajaran IPA, yang dilanjutkan dengan evaluasi, ternyata hasilnya tidak memuaskan. Pembelajaran berpusat pada dosen, dosen belum menggunakan media yang sesuai konsep materi, keterlibatan mahasiswa dalam pembelajaran kurang ada kesempatan untuk terlibat langsung dalam proses pembelajaran yang mengakibatkan mahasiswa pasif dan hasil evaluasi dengan rata-rata nilai 5,38, dari permasalahan tersebut seharusnya dosen menggunakan inovasi berbantuan media pembelajaran agar konsep materi IPA bisa lebih mudah di pahami dan menarik minat mahasiswa untuk aktif dalam proses perkuliahan.

Tenaga pendidik dalam menjalankan profesinya dituntut untuk dapat memilih, menggunakan, membuat serta mencari metode maupun media yang menarik bagi siswa agar siswa dapat benarbenar fokus terhadap pembelajaran yang dilakukan. Pemilihan media pembelajaran yang tepat dapat menunjang keberhasilan suatu pembelajaran. Arsyad 2004:106. edia berbasis visual merupakan visualisasi pesan, informasi, atau konsep yang ingin disampaikan kepada siswa yang dapat dikembangkan dalam berbagai bentuk seperti foto, gambar atau ilustrasi, sketsa, grafik, chart. 
Berdasarkan dari permasalahan di atas, media berbasis komputer dalam proses belajar mengajar sangat diperlukan. Media pembelajaran menjadi pilihan inovasi untuk dikembangkan. Media yang akan dikembangkan berupa media Office Mix. Ofiice mix merupakan bagian aplikasi terbaru dari Power Point yang diluncurkan terbaru dari Windows 2013. Keunggulan dari media pembelajaran slide power point (office mix) yaitu penyajian pembelajaran menarik karena ada permainan warna, huruf, animasi, baik animasi teks maupun animasi gambar atau foto dan lebih merangsang anak untuk mengetahui lebih jauh pesan informasi visual tentang bahan ajar yang tersaji. Sehingga dengan bantuan media ini diharapkan siswa akan lebih mudah untuk memahami materi pelajaran dan motivasi belajar siswa akan meningkat dan berdampak positif terhadap hasil belajar siswa.

\section{METODE PENELITIAN}

Penelitian ini dilaksanakan pada Program Studi Guru sekolah dasar (PGSD) Universitas PGRI Madiun tahun akademik 2016/2017. Penelitian ini termasuk penelitian eksperimen dengan pendekatan kuantitatif. Desain penelitian yang digunakan dalam penelitian ini adalah preexperimenta. Design dan jenis penelitian yang digunakan adalah Intact-Group Comparison. Dalam penelitian ini terdapat dua kelompok yang dipilih yaitu kelompok eksperimen dan kelompok kontrol. Kelompok eksperimen adalah kelompok yang diberi perlakuan (media pembelajaran slide power point (office mix)) dan kelompok kontrol adalah kelompok yang tidak diberi perlakuan. Kedua kelompok diberi pengukuran yang sama dengan menggunakan tes hasil belajar. Populasi dalam penelitian ini adalah keseluruhan mahasiswa semester 3 PGSD Universitas PGRI Madiun. Teknik pengambilan sampel pada penelitian ini adalah simple random sampling. Sedangkan sampel dalam penelitian ini adalah mahasiswa semester 3 Kelas $\mathbf{J}$ yang berjumlah 38 dan mahasiswa semester 3 kleas $\mathrm{H}$ yang berjumlah 36 . Mahasiswa kelas $\mathbf{J}$ dijadikan sebagai kelas eksperimen dan mahasiswa kelas $\mathrm{H}$ dijadikan sebagai kelas kontrol. Teknik pengumpulan data yang digunakan dalam penelitian ini adalah tes, observasi, wawancara, dan dokumentasi. Analisis data pada penelitian ini menggunakan uji t. Sebelum dilakukan analisis data, maka dilakukan uji normalitas menggunakan uju Liliefors dan uji homogenitas menggunakan uji $F$.

\section{HASIL DAN PEMBAHASAN}

Hasil analisis pengaruh penggunaan media pembelajaran slide power point (office mix) dapat dilihat pada tabel berikut.

Tabel 1 Nilai Rata-Rata Hasil Belajar IPA

\begin{tabular}{lcc}
\hline \multicolumn{1}{c}{ Ranah Hasil } & \multicolumn{2}{c}{ Rata-Rata } \\
\cline { 2 - 3 } & Eksperimen & Kontrol \\
\hline Kognitif & 81,90 & 64,76 \\
\hline Afektif & 81,55 & 63,69 \\
\hline Psikomotor & 84,12 & 67,06 \\
\hline
\end{tabular}

Berdasarkan data yang disajikan pada Tabel 1 dapat dibuat histogram perbandingan rata-rata hasil belajar IPA kelas kontrol dan kelas eksperimen seperti pada Gambar 1. 

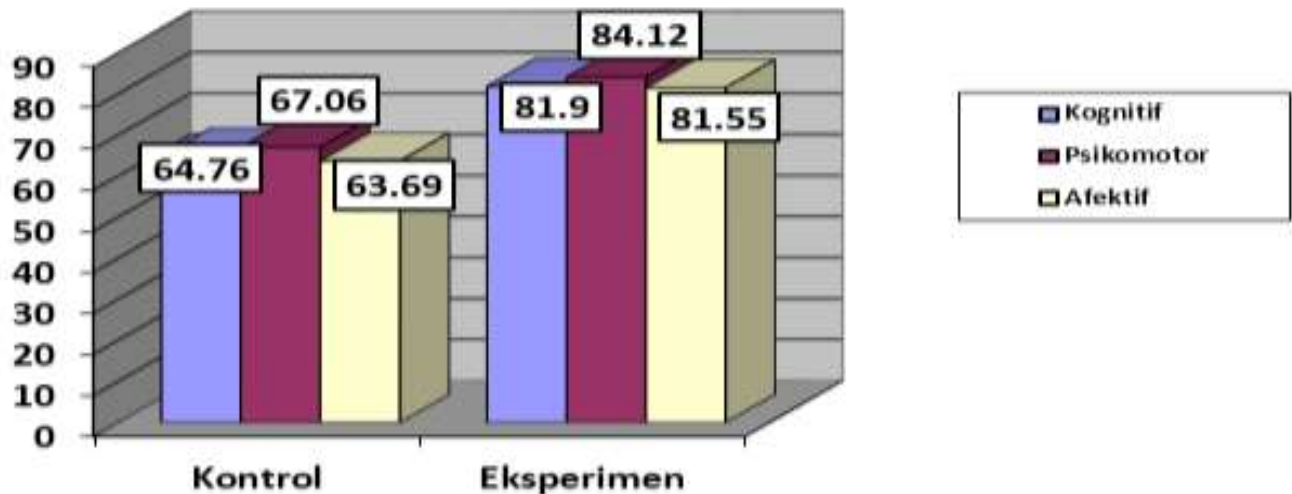

Gambar 1.Histogram Perbandingan Rata-rata Hasil Belajar IPA Kelas Kontrol dan Kelas Eksperimen.

Tabel 1 dan Gambar 1 menunjukkan bahwa rata-rata hasil belajar Pembelajaran IPA mahasiswa pada kelas eksperimen lebih tinggi daripada kelas kontrol baik dari ranah kognitif, ranah psikomotorik maupun ranah afektif. Berdasarkan hal tersebut menunjukan bahwa penerapan pembelajaran berbasis visual slide power point (office mix) mampu meningkatkan hasil belajar pembelajaran IPA.

Berikut ini adalah hasil uji normalitas dan homogenitas. Rangkuman hasil uji normalitas dapat dilihat pada tabel berikut.

Tabel 2 Rangkuman Hasil Uji Normalitas

\begin{tabular}{cccc}
\hline Kelas & Lhitung & Ltabel & Kesimpulan \\
\hline Eksperimen & 0,1691 & 0,1866 & Berdistribusi Normal \\
\hline Kontrol & 0,1230 & 0,1866 & Berdistribusi Normal \\
\hline
\end{tabular}

Berdasarkan analisis uji normalitas pada kelas eksperimen dapat diketahui nilai $\mathrm{L}_{\text {hitung }}(0,1691)<\mathrm{L}_{\text {tabel }}(0,1866)$ maka $\mathrm{H}_{0}$ diterima. Sedangkan kelas kontrol diketahui nilai $\mathrm{L}_{\text {hitung }}(0,1230)<\mathrm{L}_{\text {tabel }}(0,1866)$ maka $\mathrm{H}_{0}$ diterima, sehingga data yang diperoleh kelas eksperimen dan kelas kontrol berasal dari populasi yang berdistribusi normal.
Setelah dipastikan data berasal dari populasi yang berdistribusi normal dan varian homogen, maka selanjutnya data diuji hipotesisnya dengan menggunakan uji-t dengan taraf signifikansi $5 \%$. Rangkuman hasil uji hipotesis dapat dilihat pada tabel berikut:

Tabel 3 Rangkuman Hasil Uji Hipotesis

\begin{tabular}{ccc}
\hline $\mathbf{T}$ & Nilai & Keterangan \\
\hline$T_{\text {tabel }}$ & 1,685 & $H_{1}$ diterima karena $T_{\text {hitung }}$ \\
$T_{\text {hitung }}$ & 19,18 & $19,18>T_{\text {tabel }} 1,685$ \\
\hline
\end{tabular}

Nilai $T_{\text {hitung }}$ sebesar 19,18 dengan nilai tabel sebesar 1,684 sehingga nilai $T_{\text {hitung }} 19,18>T_{\text {tabel }} 1,685$ ehingga $\mathrm{H}_{0}$ ditolak dan $\mathrm{H}_{1}$ diterima. Jadi keputusan uji hipotesis dalam penelitian ini dinyatakan bahwa penggunaan media pembelajaran 
slide power point (office mix) efektif dilakukan pada pembelajaran IPA.

Berdasarakan data hasil penelitian bahwa ada perbedaan penggunaan media pembelajaran Slide Power Point (Office Mix) terhadap hasil belajar IPA kelas IV di SDN Singgahan 1. Penggunaan media pembelajaran Slide Power Point (Office Mix) menunjukkan hasil yang lebih baik dari pada penggunaan model pembelajaran konvensional. Hal ini ditunjukkan dengan perilaku siswa dalam belajar yaitu siswa lebih aktif, kreatif, dan kritis dalam menyelesaikan tugas yang diberikan oleh guru, sehingga mempengaruhi hasil belajar IPA.

Kegiatan pembelajaran dengan media pembelajaran Slide Power Point (Office Mix) mengakomodasi mahasiswa untuk lebih memahami konsep yang diajarkan, aktif memecahkan masalah, mahsiswa dapat lebih mandiri dan leluasa dalam mengikuti perkuliahan karena media pembelajaran Slide Power Point (Office Mix) menghadapkan mahasiswa secara langsung pada masalah yang ada. Dalam pembelajaran dengan menggunakan media pembelajaran Slide Power Point (Office Mix), mahasiswa akan belajar secara visual dan materi yang diajarkan dibuat inovatif dengan menggabungkan gambar, video yang sesuai dengan materi ke dalam Slide Power Point (Office Mix) sehingga dapat mencapai ketuntasan dalam belajar.

Suharto (2015:4) menyatakan bahwa menurut teori kognitif, kegiatan belajar ditentukan oleh tingkah laku siswa dalam mempersepsi atau memahami suatu bahan ajar. Piaget (dalam Malawi, 2013: 15) menjelaskan bahwa perkembangan kognitif sebagian besar begantung kepada seberapa jauh anak aktif memanipulasi dan aktif berinteraksi dengan lingkungannya. Keterlibatan siswa secara aktif dalam pembelajaran, menjadikan belajar siswa menjadi bermakna. Hal inilah yang mendasari kegiatan pembelajaran dengan menggunakan Slide Power Point (Office Mix) yang dapat membuat siswa lebih aktif dalam proses pembelajaran, karena pembelajaran lebih menyenangkan tidak membosankan dan menyajikan materi yang berbeda agar siswa lebih mudah memahami materi pelajaran, sehingga kegiatan belajar dapat mencapai tujuan yang diharapkan. Berbeda dengan pembelajaran dengan menggunakan pembelajaran konvensional dan tanpa menggunakan media pembelajaran. Pembelajaran dengan menggunakan tersebut hanya berlangsung dengan baik apabila kemampuan menyimak dan mendengar dengan baik, sehingga pembelajaran tersebut cepat merasakan bosan.

Teori belajar konstruktivistik, untuk mengkonstruksi pengetahuannya manusia harus menggunakan indranya. Melalui interaksinya dengan obyek dan lingkungan, misalnya dengan melihat, mendengar, menjamah, membau, atau merasakan, seseorang dapat mengetahui sesuatu. Pengetahuan bukanlah sesuatu yang sudah ditentukan, melainkan suatu proses pembentukan. Semakin banyak seseorang berinteraksi dengan obyek dan lingkungannya, pengetahuan dan pemahamannya akan meningkat dan lebih rinci (Malawi, 2013: 24).

Brunner (dalam Malawi, 2013: 16) menyarankan agar siswa hendaknya belajar melalui partisipasi secara aktif dengan konsep-konsep dan prinsip-prinsip itu sendiri. Karena pendapat tersebut dalam penelitian ini menggunakan media Slide Power Point (Office Mix) dalam pembelajaran yang berguna untuk menarik minat siswa dan memotivasi mahasiswa untuk aktif dalam proses pembelajaran sehingga siswa menemukan konsep-konsep pembelajarannya sendiri. 
Media pembelajaran Slide Power Point (Office Mix) dapat memberikan solusi yang tepat untuk mengatasi masalah hasil belajar yang ada di SDN Singgahan 1 Dimana kurangnya motivasi siswa terhadap pembelajaran IPA akan berdampak pada hasil belajar IPA, bahwa pembelajaran tidak menarik kurang inovatif dalam menggunakan media dan pembelajatan lebih ditekankan pada hafalan sehingga mahasiswa mudah lupa dan dosen masih berperan aktif seperti yang ada dalam pembelajaran konvensional. Sedangkan kendala saat menggunakan media pembelajaran Slide Power Point (Office Mix) dalam penelitian ini yaitu kurangnya sarana pendukung seperti office mix merupakan program E-Learning yang berguna untuk membuat presentasi yang dijalankan secara online, tetapi masih banyak kekurangan untuk mengaplikasikannya. Semoga dikemudian hari program ini dapat dikembangkan lebih mudah sehingga guru dapat memanfaatkannya secara maksimal untuk menunjang pembelajaran yang menarik dan memotivasi mahasiswa untuk lebih tertarik mengikuti perkuliahan.

\section{SIMPULAN}

Hasil analisis data dan pembahasan hasil penelitian dapat diambil simpulan bahwa penerapan media pembelajaran berbasis visual Slide Power Point (Office Mix) efektif dilakukan pada pembelajaran IPA mahasiswa Prodi PGSD Universitas PGRI Madiun tahun Akademik 2016/2017.

\section{DAFTAR RUJUKAN}

Arsyad, A. A. (2011). Media Pembelajaran. Jakarta: Raja Grafindo Persada.

Setyawan, B. (2012). Pengaruh Media Power Point Terhadap Peningkatan
Prestasi Belajar. Jurnal Skripsi, (http://dispendik.surabaya.go.id/suraba yabelajar/jurnal/199/4.6.pdf). Diunduh 08 April 2016.

Daryanto. (2010). Media Pembelajaran. Yogyakarta: Gava Media.

Dirman Dan Juarsih. (2014). Kegiatan Pembelajaran Yang Mendidik. Jakarta: Rineka Cipta.

Rahmawati F. (2011). Efektifitas pemanfaatan media audio visual pembelajaran dalam upaya meningkatkan motivasi dan hasil belajar. jurnal skripsi, (http://repository.uinjkt.ac.id/dspace/b itstream/123456789/3107/1/FITRIA\% 20NINGTIAS\%20RAHMAWATIFITK.pdf, diunduh 08 April 2016)

Hasanudin. (2015). Penggunaan Media Visual Untuk Meningkatkan Hasil Belajar. Jurnal Skripsi, (http://repository.uinjkt.ac.id/dspace/bi tstream/123456789/29797/1/HASAN\%20FITK.pdf), diunduh 08 April 2016).

Muslich, M. (2011). Authentic Assessment. Bandung: Refika aditama.

Prasasti, P.A.T. (2016). Effectiveness of Scientific Approach in Science Learning with PBL Setting to Empower Science Process Skills. Bioedukasi: Jurnal Pendidikan Biologi, 9(2), 14-20.

Prasasti, P. A. T. (2012). Pengaruh Penerapan Strategi Pembelajaran Active Knowledge Sharing Terhadap Keterampilan Proses Sains dan Hasil Belajar Ranah Kognitf dan Ranah Afektif Siswa Kelas X Semester Genap SMA Negeri 2 Karanganyar Tahun Pelajaran 2011/2012.

Prasasti, P. A. T. (2014). Pengembangan Modul Berbasis Problem Based Learning (Pbl) Disertai Fishbone Diagram pada Materi Pencemaran Lingkungan Untuk Memberdayakan Keterampilan Proses Sains (KPS) dan 
Kemampuan Menganalisis (Penelitian Pengembangan di SMA Negeri 2 Karanganyar Tahun (Doctoral dissertation, UNS (Sebelas Maret University)).

Purwanto. (2011). Evaluasi Hasil Belajar. Yogyakarta: Pustaka Belajar.

Rusman. (2013). Belajar Dan Pembelajaran Berbasis Komputer. Bandung: Alfabeta
Sholikhah, O. H. (2017). Implementation Of Quantum Teaching Learning Viewed From Multiple Intelligences in Mathematics Learning In Proceeding Internasional Seminar of Primary Education (Vol. 1).

Sanjaya, W. (2012). Media Komunikasi Pembelajaran.Jakarta: Kencana Prenado Meda Group. 
62 JURNAL PENDIDIKAN EDUTAMA, Vol.5, No.2 Juli 2018 